\title{
CURRÍCULO POR CAMPOS DE EXPERIÊNCIA NA EDUCAÇÃO INFANTIL: AINDA É POSSÍVEL PRESERVAR O ENSINO DESENVOLLENTE?
}

\author{
CURRÍCULO POR CAMPOS DE EXPERIENCIA EN LA EDUCACIÓN INFANTIL: \\ ¿ÉS POSIBLE PRESERVAR LA ENSEZANZA DESARROLLANTE?
}

\section{CURRICULUM PER EXPERIENCE FIELDS IN EARLY CHILDHOOD EDUCATION: IS IT (STILL) POSSIBLE TO PROMOTE OBUTCHENIE?}

\author{
Juliana Campregher PASQUALINI ${ }^{1}$ \\ Lígia Márcia MARTINS ${ }^{2}$
}

\begin{abstract}
RESUMO: O presente artigo efetua a caracterização geral e o exame crítico daquilo que impõe a legislação atual para a Educação Infantil, com o objetivo explorar caminhos possíveis para a formulação de propostas curriculares de orientação histórico-crítica diante da vigência da noção de "campos de experiência". A partir da análise do capítulo da Base Nacional Comum Curricular dedicado à Educação Infantil e do documento "Campos de experiências: efetivando direitos e aprendizagens na Educação Infantil”, de 2018, identificam-se aspectos válidos e problematiza-se a persistência do enfoque antiescolar e da concepção liberal e idealista de educação. Conclui-se com busca de caminhos possíveis para o trabalho pedagógico colocando em tela as experiências infantis e seus conteúdos.
\end{abstract}

PALAVRAS-CHAVE: Educação infantil. Base Nacional Comum Curricular. Pedagogia histórico-crítica. Escola de Vigotski.

RESUMEN: El artigo efectúa la caracterización general y el examen crítico del que impone la legislación actual para la educación de niños menores de seis años en Brasil, con el objetivo de búsqueda de caminos posibles para la formulación de proposiciones curriculares de orientación histórica-crítica frente a la vigencia de la noción de "campos de experiencia". El análisis del capítulo de la Base Nacional Común Curricular dedicado a la Educación Infantil $y$ del documento "Campos de experiencias: garantizando derechos y aprendizaje en la Educación Infantil”, de 2018, lleva a la identificación de aspectos válidos y problematización de la persistencia del enfoque anti-escolar y de la concepción liberal y idealista de educación. El artigo se concluye con la exploración de caminos posibles para el trabajo pedagógico, focalizando las experiencias infantiles y sus contenidos.

PALABRAS CLAVE: Educación infantil. Base Nacional Común Curricular. Pedagoga histórico-crítica. Vigotski.

1 Universidade Estadual Paulista (UNESP), Bauru - SP - Brasil. Docente do Departamento de Psicologia (UNESP/Bauru) e do Programa de Pós-Graduação em Educação Escolar (UNESP/Araraquara). Pós-Doutorado em Ciências Humanas (UNICAMP). ORCID: https://orcid.org/0000-0002-6497-8783. E-mail: juliana.pasqualini@unesp.br

${ }^{2}$ Universidade Estadual Paulista (UNESP), Bauru - SP - Brasil. Docente aposentada do Departamento de Psicologia (UNESP/Bauru). Professora credenciada no Programa de Pos-Graduação em Educação Escolar (UNESP/Araraquara). Livre Docente em Psicologia da Educação (UNESP). ORCID: https://orcid.org/0000-00024293-9580. E-mail: ligia.martins@unesp.br

RPGE- Revista on line de Política e Gestão Educacional, Araraquara, v. 24, n. 2, p. 425-447, maio/ago., 2020. e-ISSN: 1519-9029. DOI: https://doi.org/10.22633/rpge.v24i2.13312 (c) $\mathrm{BY}-\mathrm{NC}-\mathrm{SA}$ 
ABSTRACT: This paper presents a general characterization and critical examination of what the current Brazilian legislation for Early Childhood Education imposes, with the aim of exploring possible paths for the formulation of curricular proposals of historical-critical orientation in the face of the notion of "experience fields". Based on the analysis of the chapter of the "Base Nacional Comum Curricular" (National Common Curricular Base) dedicated to Early Childhood Education and the document "Campos de experiências: efetivando direitos e aprendizagens na Educação Infantil" (Experience fields: assuring rights and learning in Early Childhood Education), launched in 2018, valid aspects are identified at the same time as the persistence of the anti-schooling approach and its liberal and idealistic conception of education is problematized. The paper concludes with the search for possible paths for pedagogical work, by focusing children's experiences and their contents.

KEYWORDS: Early childhood education. National Common Curricular Base. Criticalhistorical pedagogy. Vygotski.

\section{Introdução}

Em 22 de dezembro de 2017, a Resolução CNE/CP n. 02/17 instituiu a Base Nacional Comum Curricular (BNCC), “documento de caráter normativo que define o conjunto orgânico e progressivo de aprendizagens essenciais como direito das crianças, jovens e adultos no âmbito da Educação Básica escolar” (BRASIL, 2017). Em que pese o caráter normativo da Base, permanece garantida a autonomia das instituições escolares e respectivos sistemas de ensino, prevista nos artigos 12, 13 e 23 da Lei de Diretrizes e Bases da Educação Nacional, que "poderão adotar formas de organização e propostas de progressão que julgarem necessários", como se lê no Parágrafo Único do Artigo $1^{\circ}$ da referida Resolução.

A compreensão daquilo que se coloca como mandatório e - ao mesmo tempo - do espaço de autonomia dos sistemas de ensino e instituições escolares pressupõe estabelecer a diferença entre Base Comum Curricular e currículo. A Base Nacional Comum Curricular (BNCC) é promulgada com o propósito proclamado de "definir os direitos e objetivos de aprendizagem das crianças" (FUNDAÇÃO SANTILLANA, 2018, p. 5), assumindo papel orientador em relação ao currículo: "ela não constitui um currículo, embora deva orientá-lo" (p. 5). O currículo, por sua vez, "é formado pelo conjunto de situações cotidianas organizadas para as crianças em cada unidade de Educação Infantil com base em seu projeto pedagógico" (p. 5, grifo nosso). Em conformidade com a LDB em seu artigo $12^{\circ}$, a elaboração e execução de propostas pedagógicas é incumbência dos estabelecimentos de ensino, respeitadas as normas comuns (e do respectivo sistema de ensino).

No presente artigo, tomamos como objeto as proposições da BNCC referentes à educação infantil, buscando estabelecer um diálogo crítico e ao mesmo tempo propositivo com 
as diretrizes da Base para esse segmento de ensino a partir dos fundamentos histórico-críticos da pedagogia e histórico-culturais da psicologia.

Municípios e coletivos que esposam a pedagogia histórico-crítica se enfrentam hoje com o desafio de atender as novas normativas legais sem desvirtuar ou descaracterizar seu projeto de formação humana, vez que a BNCC não possui fundamento histórico-crítico ${ }^{3}$. Como buscaremos evidenciar, o preconizado pela Base representa continuidade e aprofundamento do enfoque construtivista, desescolarizante e assistemático sobre o trabalho pedagógico com a criança pequena, o qual conquistou hegemonia nas últimas décadas, materializando-se nos documentos oficiais anteriores. Defronte a esse cenário, o presente artigo foi elaborado com o objetivo de explorar caminhos possíveis para a formulação de propostas curriculares por instituições escolares e sistemas de ensino que elegem como referência teórico-metodológica a pedagogia histórico-crítica e a psicologia histórico-cultural.

A pergunta que serve como fio condutor das reflexões que aqui apresentaremos é: diante das novas determinações oficiais, que impõem a noção de "campos de experiência" como estruturante do currículo da educação infantil, ainda é possível preservar o ensino desenvolvente? O tratamento que aqui conferiremos aos campos de experiência tem como perspectiva auxiliar a criação de algum valor pedagógico a partir daquilo que hoje, lamentavelmente, se impõe como força legal organizativa para as escolas de Educação Infantil.

As análises e proposições aqui veiculadas são derivadas do exame crítico do capítulo da BNCC dedicado à Educação Infantil, bem como do documento "Campos de experiências: efetivando direitos e aprendizagens na Educação Infantil", publicado em 2018. Trata-se de material lançado em 2018 pelo Ministério da Educação em cooperação com a UNESCO, com produção editorial da Fundação Santillana e apoio da Fundação Maria Cecília Souto Vidigal e do Movimento pela Base Nacional Comum, cujo texto final, conforme dados de catalogação da publicação, é de Zilma de Moraes Ramos de Oliveira. Trata-se, portanto, de uma investigação que se caracteriza metodologicamente como análise documental, amparada no sistema conceitual da teoria pedagógica histórico-crítica. Nosso percurso principiará com uma caracterização geral daquilo que propõe (ou impõe) a BNCC para a Educação Infantil, detendose, em seguida, nos aspectos positivos ou válidos da proposta segundo parâmetros históricocríticos. O terceiro movimento do texto será problematizar a persistência do enfoque antiescolar na Educação Infantil e seu caráter idealista e liberal. Por fim, nos dedicaremos à busca de

${ }^{3}$ Assertiva que afirme tal contiguidade só pode resultar de leituras e interpretações superficiais e aligeiradas - e por isso equivocadas - sobre a psicologia histórico-cultural e a pedagogia histórico-crítica, ou, ainda, de uma boa dose de má-fé, tão comum entre os ideólogos da burguesia e entre os empresários da educação. 
caminhos possíveis para o trabalho pedagógico colocando em tela as experiências infantis e seus conteúdos.

\section{O que dispõe a BNCC sobre a Educação Infantil?}

O capítulo da BNCC intitulado "A etapa da Educação Infantil” tem 21 páginas, já contemplada, nesse intervalo, a discussão sobre a transição para o Ensino Fundamental. A proposta para o segmento organiza-se à base de quatro elementos fundantes: I) direitos de aprendizagem; II) campos de experiência; III) objetivos de aprendizagem e desenvolvimento; IV) grupos etários. Preservam-se, também, interações e brincadeiras como eixos estruturantes das práticas pedagógicas, conforme preconizado nas Diretrizes Nacionais Curriculares para a Educação Infantil (DNCEI), todavia, em nossa análise, estes comparecem mais como princípio geral e pano de fundo do que propriamente elemento organizador (estruturante) da proposta.

Os direitos de aprendizagem situam-se no âmbito da intencionalidade pedagógica geral. São seis os direitos de aprendizagem a serem garantidos às crianças: conviver, brincar, participar, explorar, conhecer-se, expressar. A concretização desses direitos, na proposta em questão, vincula-se especialmente à possibilidade de constituir-se como sujeito dialógico, criativo e sensível, acessando produções culturais (as artes, a escrita, a ciência e a tecnologia), ampliando o conhecimento de si e do outro, desenvolvendo diferentes linguagens e construindo uma imagem positiva de si e de seus grupos de pertencimento.

Os direitos de aprendizagem desdobram-se em objetivos de aprendizagem, dentro de uma organização curricular por campos de experiência, como se lê no seguinte excerto:

Considerando que, na Educação Infantil, as aprendizagens e o desenvolvimento das crianças têm como eixos estruturantes as interações e a brincadeira, assegurando-lhes os direitos de conviver, brincar, participar, explorar, expressar-se e conhecer-se, a organização curricular da Educação Infantil na BNCC está estruturada em cinco campos de experiências, no âmbito dos quais são definidos os objetivos de aprendizagem e desenvolvimento. Os campos de experiências constituem um arranjo curricular que acolhe as situações e as experiências concretas da vida cotidiana das crianças e seus saberes, entrelaçando-os aos conhecimentos que fazem parte do patrimônio cultural (BRASIL, 2017, p. 38).

Os campos de experiência configuram um conceito de ordem mais especificamente metodológica, ou seja, referem-se mais diretamente ao modo de condução do trabalho pedagógico. A adoção de tal modelo de arranjo curricular é justificada como estratégia para fomentar “[...] práticas abertas às iniciativas, desejos e formas próprias de agir da criança que, mediadas pelo professor, constituem um contexto rico de aprendizagens significativas" 
(FUNDAÇÃO SANTILLANA, 2018, p. 10). Os proponentes consideram que a adoção do arranjo por campos de experiência traz implicações significativas para a organização dos contextos de aprendizagem na educação infantil, “[...] modificando maneiras tradicionais de planejar e efetivar as práticas pedagógicas por ser muito diferente da estrutura baseada em áreas do conhecimento, mais familiar aos currículos efetivados no Ensino Fundamental" (FUNDAÇÃO SANTILLANA, 2018, p. 10). São cinco os campos de experiência indicados pela BNCC: o eu, o outro e o nós; corpo, gestos e movimentos; traços, sons, cores e formas; escuta, fala, pensamento e imaginação; espaços, tempos, quantidades, relações e transformações.

Vinculados a cada um dos campos, são delimitados objetivos de aprendizagem e desenvolvimento, que contemplam comportamentos, habilidades e conhecimentos a serem construídos pelas crianças a partir de interações e brincadeiras ${ }^{4}$. Além de vinculados a determinado campo de experiência, os objetivos de aprendizagem e desenvolvimento são sequencialmente organizados em três grupos etários: bebês, de zero a 1 ano e 6 meses; crianças bem pequenas, de 1 ano e 7 meses a 3 anos e 11 meses; e crianças pequenas, de 4 anos a 5 anos e 11 meses. O texto da Base não informa qual o fundamento científico da periodização etária adotada, limitando-se a justificar que "[...] correspondem, aproximadamente, às possibilidades de aprendizagem e às características do desenvolvimento das crianças", alertando que "[...] esses grupos não podem ser considerados de forma rígida, já que há diferenças de ritmo na aprendizagem e no desenvolvimento das crianças que precisam ser consideradas na prática pedagógica" (BRASIL, 2017, p. 44).

As 21 páginas dedicadas à Educação Infantil no documento da BNCC são evidentemente insuficientes para se explicitar concretamente aquilo que se propõe/impõe para essa etapa da escolarização, em especial considerando-se ser o arranjo dos campos de experiência muito pouco (ou nada) familiar às escolas e profissionais de educação infantil do território nacional. O já mencionado documento lançado em 2018 com o título "Campos de experiências: efetivando direitos e aprendizagens na Educação Infantil" vem, nesse sentido, suprir a lacuna de esclarecimento da proposta da BNCC para o trabalho pedagógico com crianças menores de seis anos. O objetivo anunciado do material é "servir de referência para os professores e demais profissionais que atuam na Educação Infantil construírem o currículo de sua unidade [...]” (FUNDAÇÃO SANTILLANA, 2018, p. 4) a partir do conceito de campo de

${ }^{4}$ A cada objetivo de aprendizagem corresponde um código alfanumérico, o que, conforme análise de Luís Carlos de Freitas no artigo "BNCC: como os objetivos serão rastreados", publicado em Avaliação Educacional - Blog do Freitas, em 2017, insinua a nefasta intenção de realização de avaliações censitárias em escala nacional como a Prova Brasil. 
experiências proposto na Base Nacional Comum Curricular (BNCC), tendo em vista "ser a organização curricular por campo de experiências relativamente nova no marco legal brasileiro [...]." (p. 4).

O documento estrutura-se em nove partes. A apresentação é feita em uma página e seguida de um texto introdutório de nove páginas que elenca os "princípios políticos, éticos e estéticos" e as "aprendizagens essenciais" propostas pela BNCC, aos quais se soma uma explicação da organização curricular por campos de experiência, sendo destacada a concepção de criança na qual esta se baseia. Na sequência, cinco capítulos são dedicados, respectivamente, aos cinco campos de experiência propostos na BNCC. O documento é concluído com um capítulo dedicado a considerações finais sobre os direitos de aprendizagem e uma lista de indicações de leitura para aprofundamento.

Os capítulos particularmente dedicados aos campos de experiência apresentam estrutura semelhante, composta de seis momentos, assim dispostos: i) introdução; ii) apresentação de conceitos básicos; iii) apresentação do campo de experiência conforme texto original da BNCC; iv) discussão sobre os seis direitos de aprendizagem no campo específico; v) orientações gerais quanto ao processo pedagógico (eventualmente subdivididas em tópicos); vi) discussão sobre o papel do professor e a garantia dos direitos de aprendizagem no campo específico, contendo três tópicos referentes aos objetivos de aprendizagem agrupados por faixa etária. Os cinco capítulos são concluídos com um quadro intitulado "Atenção", no qual se faz algum alerta ou destaque em relação a possíveis equívocos de compreensão da proposta de trabalho.

\section{A positividade da proposta em análise}

Uma análise detida do documento "Campos de experiências: efetivando direitos e aprendizagens na Educação Infantil” permite identificar méritos que devem aqui ser atestados, haja vista sua convergência com o projeto histórico-crítico de educação escolar e formação humana. Destacamos: a ênfase na atitude de cuidado, acolhimento, apoio e respeito dos adultos para com a criança; o posicionamento de combate às desigualdades de gênero e diversas formas de exclusão típicas de nossa sociedade que se reproduzem no contexto escolar; a determinação de inclusão de crianças com deficiências diversas nos variados momentos da rotina escolar; a atuação docente coibindo preconceitos, agressões e assédios e garantindo tratamento igualitário entre meninos e meninas. Postula-se, ainda, a necessidade de garantir um ambiente tranquilo, no qual se cultivem relações cooperativas e democráticas. 
Sublinhamos, ademais, os seguintes indicativos distribuídos ao longo do texto: a escuta e o olhar atentos às crianças; a sensibilidade para identificar e acolher suas demandas e necessidades; a atenção e consideração à maneira como as crianças reagem ao que lhes é proposto e ao significado que as atividades têm na experiência infantil; a necessária delicadeza do trato e a importância da interação comunicativa nos momentos de cuidado; a importância de estimular a reflexão da criança sobre os fenômenos e objetos que a rodeiam; a exigência de um "preparo zeloso do ambiente" (FUNDAÇÃO SANTILLANA, 2018, p. 48) de modo a garantir um espaço limpo, seguro, amplo e uma rotina que evite o confinamento e o sedentarismo.

A abrangência da proposta é um aspecto que merece destaque, pois, em seu conjunto, os cinco campos contemplam experiências sensoriais, corporais, estéticas e intelectuais, preconizando o contato ativo das crianças com práticas sociais e culturais de natureza artística, científica, filosófica e da cultura corporal. A oportunidade de acesso a bens culturais e ampliação de saberes é reivindicada como tarefa da educação infantil. O documento frisa a importância de se proporcionar "experiências ricas e diversificadas" (FUNDAÇÃO SANTILLANA, 2018, p. 30) que colaborem para "ampliar o desenvolvimento pleno das crianças" (p. 28), fomentando o compromisso de "possibilitar que todas as crianças se apropriem de diferentes linguagens e tenham disponíveis materiais para se expressar" (p. 7).

Sopesando a realidade das escolas (públicas e privadas) de educação infantil brasileiras, que por diversas e complexas razões se mostram ainda lamentavelmente tão marcadas por condutas que buscam subjugar as crianças pelo medo (controle do comportamento por broncas, ameaças, punições), alimentam e reproduzem desigualdades de várias ordens, e impõem às crianças rotinas esvaziadas de conteúdo cultural e tarefas sem sentido - resultando em uma experiência escolar absolutamente empobrecida, salientamos a relevância dos indicativos acima referidos. Considerando o projeto de plena humanização de toda criança que norteia a pedagogia histórico-crítica, entendemos que essa teoria necessariamente convida - ou conclama - o professor a combater e superar tais práticas que malogram a experiência escolar infantil. Isso significa que a prática pedagógica de orientação histórico-crítica e histórico-cultural garante plenamente o que na BNCC se identifica como direito a conviver, brincar, participar, explorar, conhecer-se e se expressar; a divergência, ou crítica, como veremos, reside no aspecto assistemático e minimalista (no que se refere aos conteúdos) do arranjo curricular por campos de experiência, o que deriva de diferenças em termos do horizonte de formação esperada para as crianças, e da própria compreensão do que seja a experiência humana no mundo. O olhar histórico-crítico nos faz questionar a ausência, entre o rol de direitos de aprendizagem, do direito a conhecer o mundo. 


\section{A persistência do enfoque antiescolar sobre a educação infantil}

Feita a apresentação geral da proposta e destacados seus aspectos positivos, passamos ao exame dos aspectos que evidenciam divergências em relação ao que preconiza a perspectiva pedagógica de orientação histórico-crítica e histórico-cultural. Nosso esforço nesse tópico será evidenciar a plena vigência, na BNCC, da concepção idealista e liberal de educação, sociedade e desenvolvimento humano.

Sustentamos anteriormente que a prática pedagógica histórico-crítica garante plenamente os direitos de aprendizagem estabelecidos pela BNCC. Não obstante, é preciso esclarecer quais são as diferenças no âmbito dos fundamentos ético-políticos que guiam os meios e caminhos pelos quais tais direitos serão garantidos. As orientações ao professor cuja positividade destacamos no tópico anterior se justificam, no âmbito da Base, pelo declarado compromisso com "a igualdade de direitos de todas as pessoas e entre homens e mulheres, assim como a solidariedade com indivíduos de grupos sociais vulneráveis" (FUNDAÇÃO SANTILLANA, 2018, p. 6). É preciso demarcar que o senso de igualdade e de solidariedade são evidentemente convergentes como o projeto histórico-crítico de educação escolar, mas é mister que se parta de uma visão crítica de sociedade, que desvela a divisão em classes sociais e as relações de poder e dominação que a reproduzem e sustentam. Uma vez que não se analisam os determinantes estruturais produtores de desigualdade e o papel concreto da escola no processo de perpetuação ou combate a tais mecanismos, a bandeira da igualdade pode assumir contorno idealista. Da mesma forma, se não se demarca a defesa da igualdade substantiva, cimentada no plano das condições concretas e não apenas das concepções e dos direitos formais, a igualdade de direitos pode se achar confinada a uma visão liberal de educação e sociedade, que toma a sociedade como mero habitat de indivíduos em interação na busca de satisfação de seus interesses particulares. Apontamos, assim, a necessidade de articulação da luta pelo direito à educação de qualidade à luta pela transformação das estruturas sociais produtoras da exclusão e da marginalidade, perspectiva claramente ausente na BNCC.

À concepção (neo)liberal de sociedade articula-se o projeto educativo subjacente à BNCC, que no particular contexto da Educação Infantil expressa-se a partir do ideário antiescolar. É nítida tanto no texto da BNCC quanto do documento complementar em análise a opção por não utilizar os termos escola, ensino, aluno, aula. "Não se trata de pensar em aulas de educação física na educação infantil” (FUNDAÇÃO SANTILLANA, 2018, p. 34, grifo nosso), alerta o capítulo dedicado ao campo "corpo, gestos e movimento". "Atitudes como a de 
transmissão de conhecimentos já sistematizados na cultura que deverão ser aprendidos pelas crianças também precisam ser superadas", orienta o texto introdutório (p. 8).

Trata-se da clara persistência do enfoque antiescolar, para o qual o ato de ensinar seria inadequado, indesejável ou mesmo prejudicial à criança menor de 6 anos; creches e pré-escolas não deveriam ser consideradas, tratadas ou organizadas como escolas; e não se deveria considerar ou tratar a criança menor de 6 anos como aluno, pois isso representaria um desrespeito a sua infância (PASQUALINI, 2006). Na síntese de Lamare (2016), que em sua tese de doutorado analisa a concepção de formação humana nas políticas de Educação Infantil no Brasil a partir do exame de documentos oficiais de 2003 a 2010, trata-se da hegemonia de uma perspectiva não-diretivista segundo a qual creches e pré-escolas (destinadas à classe trabalhadora) devem orientar-se pelo objetivo de promover relações educativas que auxiliem a criança a "acreditar em si”, de modo que ela possa viver de modo prazeroso e feliz. O trabalho pedagógico e o conteúdo escolar são relegados a segundo plano em nome do enaltecimento das experiências espontâneas infantis. É nesse bojo que podemos compreender a proposição do currículo por campos de experiência, em detrimento das áreas do conhecimento. Conforme Pasqualini (2018, p. 164-165):

[...] os campos de experiência (ou campos de formação) aparecem como alternativa - para o contexto particular da educação infantil - ao currículo em sua formatação clássica por disciplinas ou áreas de conhecimento. O rechaço à organização do currículo da educação infantil por áreas de conhecimento configura, em nossa avaliação, uma suposta solução para preservar a especificidade da EI que na verdade expressa o ceticismo epistemológico diante da ciência e da possibilidade de conhecimento objetivo sobre a realidade, próprias do pensamento pós-moderno, cujas consequências nefastas para a educação já foram claramente evidenciadas por Duarte (2001).

É relevante pontuar que as consequências da perspectiva antiescolar, que acaba por enaltecer modelos informais e assistemáticos de educação infantil (MARTINS; MAGALHÃES, 2014), se tornam ainda mais preocupantes em uma conjuntura na qual ganha força o ensino domiciliar ganha força, como uma das expressões daquilo que Duarte (2018) tem denominado de obscurantismo beligerante. A educação infantil, apenas a partir de 1996 incorporada ao sistema de educação e muito recentemente tendo conquistado o status de compulsoriedade a partir dos 4 anos de idade, sem dúvida é o segmento de maior fragilidade diante do fortalecimento da perspectiva de se retroceder ao enclausuramento da formação da criança pequena ao ambiente doméstico, ao privado, ao jugo exclusivo da família.

Nesse debate, queremos colocar em foco na análise da política o fato de que o conceito de experiência não é objeto de conceituação propriamente teórica na BNCC, nem no documento 
complementar. O principal recurso de explicação, como se nota no excerto a seguir, é o exemplo:

O conceito de experiência reconhece que a imersão da criança em práticas sociais e culturais criativas e interativas promove aprendizagens significativas, momentos plenos de afetividade e descobertas. Algumas dessas práticas na Educação Infantil, entre muitas outras, são cantar e dançar com outras crianças, admirar-se em frente ao espelho, comer uma refeição saborosa e cheirosa, jogar bola como se fosse um atleta, escutar histórias e emocionarse com os personagens, brincar de faz de conta, organizar com cuidado uma coleção de objetos e observar com curiosidade o que ocorre quando dois líquidos de densidade diferente são misturados, entre outras práticas, desde que respeitados seu ritmo de ação, sua iniciativa, e os sentidos que constroem (BNCC, 2017, p. 12).

O que se entende, afinal, por experiência? É preciso enfrentar essa questão, sob pena de que a política educacional seja lida e apreendida com base em significações de senso comum. Embora os documentos analisados não sejam explícitos quanto a sua fundamentação, podemos inferir que a propositura dos campos de experiência, tal como anunciados, possui um cunho idealista, carregando em si vestígios do enfoque kantiano que baliza a epistemologia genética de Jean Piaget, lastro teórico do construtivismo em suas inúmeras vertentes. Afirmamos tratarse de uma inferência a partir de vestígios haja vista a frágil sustentação teórico-conceitual da Base em seu conjunto.

Atentemos para os pressupostos kantianos que, séculos à frente, virão subsidiar o enfoque piagetiano. Para Kant, conforme análise de Russell (1969), nenhum conhecimento pode suplantar a experiência, mas ele (conhecimento) sempre será um a priori dela. Ainda segundo esse expoente da filosofia moderna, o mundo exterior só produz a matéria da sensação, mas é o aparelho mental que, ordenando esta matéria no espaço e no tempo, formula os conceitos pelos quais a realidade se torna compreensível. A constituição mental seria, então, de tal natureza que quaisquer coisas experienciadas pelo sujeito lhe revelariam as características de que se ocupam.

Em Kant, os objetos dados à percepção imediata são devidos, em parte, a coisas externas e, em parte, ao próprio aparelho perceptivo por meio das formas inatas de sensibilidade. $\mathrm{Ou}$ seja, aquilo que aparece na percepção, chamado por Kant de "fenômeno" (RUSSELL, 1969, p. 262) se constitui de duas faces: uma referente ao objeto e vivida como sensação e outra, devida ao aparelho mental individual que percebe, ordena e confere forma ao objeto da captação sensorial. Essa segunda face, não sendo sensação, não depende do objeto ou fenômeno, manifestando-se como uma forma pura de sensibilidade ou intuição, isto é, como razão pura. 
Nas palavras de Russell (1969, p. 264) referindo-se a Kant: “[...] a única maneira pela qual minha intuição pode antecipar o que se encontrará no objeto é se ele contiver apenas a forma de minha sensibilidade, antecedendo em minha subjetividade todas as impressões reais". Nota-se, nesse enfoque filosófico, a prevalência da 'mente' em relação ao objeto e, igualmente, os impasses ou obstáculos para a construção do conhecimento objetivo. Tendo em vista que as sensações serão sempre sensações produzidas pelos sujeitos particulares, caberá a elas subsidiar a percepção acerca do objeto e pouco, ou nada, acerca daquilo que o objeto realmente é. Por essa via, Kant identifica o conhecimento com a imagem que a consciência produz, por meio da organização das sensações acerca do objeto percebido. Todavia, seu sistema filosófico não supera as cisões entre sujeito e objeto e entre dedução e indução, que permanecem como marcas fortemente presentes na filosofia. No contraponto entre 'mente' e 'matéria', entre individual e universal, o idealismo kantiano é categórico em afirmar a prevalência dos primeiros sobre os segundos.

Tais preceitos subjazem na epistemologia genética de Jean Piaget, conforme apontam Martins e Marsiglia (2015), perpetuando o dualismo entre sujeito e objeto, entre indivíduo e sociedade, entre natureza e cultura, que se objetivam numa concepção de ser humano fundamentalmente natural/individual que gradativamente e por força das interações com o meio se torna social. Com isso, e sob tais referências, o dilema entre subjetividade e objetividade no que se refere ao desenvolvimento psíquico resulta insolúvel, ainda que confira destaque aos dispositivos naturais da espécie. Piaget (1982) aparentemente solucionou esse problema epistemológico e gnosiológico por meio dos conceitos de assimilação, acomodação e adaptação, explicitando uma interpretação acerca do desenvolvimento da inteligência humana baseada nas relações imediatas, sensíveis, que se estabelecem entre o organismo individual e o meio ambiente.

Nesse diapasão, a adaptação do organismo ao meio resulta exitosa à medida que o organismo equilibra internamente os conteúdos assimilados a partir dos elementos da realidade com os quais interage e acomoda essa realidade externa aos esquemas mentais internos. Essa tarefa, por sua vez, só pode ser efetivada pelo indivíduo, posto tratar-se de um expediente que resulta absolutamente da relação do sujeito com o objeto. Daí que, se o sujeito aprende interagindo com o meio, seu desenvolvimento resulta daquilo que ele vive, experiencia, a partir do seu próprio interesse pessoal e particular. Sendo assim, caberia à escola respeitar tais interesses e esforçar-se para atendê-los, numa clara afinidade aos preceitos escolanovistas, ao conferirem centralidade à subjetividade dos alunos, em detrimento da objetividade do conhecimento e do trabalho pedagógico. 
A nosso juízo, eis as bases da Base, que justificam, inclusive, a proposição dos campos de experiência para a organização da Educação Infantil como estratégia de escamotear o conhecimento como eixo articular do currículo. Tal enfoque, no mínimo, relativiza a possibilidade de existência de um conhecimento objetivo, que seja maximamente fidedigno à realidade que representa, pressuposto esse que coaduna-se harmonicamente ao ideário pósmoderno, ao questionar as metanarrativas, com destaque aos conhecimentos científicos, universais. Este preceito recoloca o papel da escola, afastando-a de sua função originária e essencial, isto é, o de transmitir os conhecimentos historicamente sistematizados às novas gerações. Resta-lhe, por conseguinte, corroborar que os alunos aprendam a aprender, sob um enfoque que faz a mais absoluta assepsia acerca da natureza dos conteúdos desta aprendizagem e, mais do que isso, acerca da dimensão valorativa do conhecimento e da educação escolar, isto é, que os alunos aprendam o quê, para quê e a serviço de quem.

Torna-se compreensível, perante o exposto, que o professor seja demovido da "atitude de transmitir conhecimento", uma vez que se arvora que o conhecimento é uma construção do sujeito particular. Essa assertiva encontra respaldo em Coll (1996), ao afirmar que o construtivismo apoia-se em três ideias fundamentais: 1) o aluno é o principal responsável por sua aprendizagem; 2) cabe à escola possibilitar que o aluno 'reconstrua' - num processo que só pode ser individual, o conhecimento já elaborado socialmente, dado que dependerá de seus interesses; 3) ao professor cumpre a tarefa de organizar os contextos interativos de modo a suscitar os interesses do aluno, guiando-o para que ocorra assimilação, acomodação e consequente adaptação do sujeito às representações sociais relativas ao meio.

Ao longo dos documentos analisados, notadamente no material de 2018 complementar à BNCC, identificamos algumas incumbências atribuídas ao profissional professor: estruturar o ambiente, criar e/ou organizar situações, oferecer materiais, propor atividades, comentar as ações infantis, avaliar as produções, orientar/comunicar instruções, incentivar/estimular a reflexão, garantir a regularidade das propostas. Vale notar que se o professor é demovido da "atitude de transmissão de conhecimento", como anteriormente pontuado, é também orientado a superar “[...] a atitude de apenas apoiar o que elas [as crianças] já manifestam (FUNDAÇÃO SANTILLANA, 2018, p. 8), garantindo, para tanto, a articulação das experiências infantis com os conhecimentos culturais já sistematizados. Observamos, assim, que ao texto do documento subjaz uma concepção negativa do ato de ensinar (DUARTE, 1998), coerente com a perspectiva construtivista, mas à medida que se propõe a um tratamento mais pormenorizado do cotidiano da prática pedagógica, torna-se impossível retirar totalmente do docente o papel condutor do processo educativo como desejariam os mais ortodoxos partidários do movimento antiescolar: 
propor atividades que garantam o acesso aos bens culturais consta entre o rol de atribuições do professor. Da mesma forma, como buscaremos evidenciar no item a seguir, é impossível eliminar completamente a referência aos conteúdos curriculares.

\section{As experiências infantis e seu conteúdo: em busca de caminhos}

Sustentamos que a psicologia histórico-cultural e a pedagogia histórico-crítica oferecem as ferramentas conceituais necessárias para compreender efetivamente a "experiência" escolar infantil e o papel que o conhecimento nela desempenha - ou deve desempenhar tendo em vista o projeto de plena humanização. Ambas teorias, vinculadas por fundamentos epistemológicos comuns, suplantam o subjetivismo e apoiam-se na compreensão da unidade dialética sujeitoobjeto, no interior da qual desponta como mediação a categoria atividade.

Superando a ideia de que as pessoas aprendem pela mera interação com o meio mobilizadas por seus interesses pessoais/particulares, a psicologia histórico-cultural vem afirmar que é por meio da atividade social que os indivíduos se relacionam com seu entorno físico e cultural tendo em vista atender suas necessidades, num processo que é, ao mesmo tempo, também gerador de novos e mais complexos carecimentos. A atividade social humana, movida por necessidades e orientada a objetos (tangíveis e intangíveis), realiza-se sob a forma de ações e operações que colocam em movimento os processos psíquicos da pessoa à medida que ela trava relação com certos aspectos da vida social e material, acessando o patrimônio histórico-cultural do gênero humano e implicando-se com os problemas da prática social.

É postulado central do enfoque histórico-cultural e histórico-crítico que o desenvolvimento humano subjuga-se às condições de vida e de educação que sustentam a relação entre sujeito e objeto, ou, mais precisamente, à qualidade das mediações que pautam a relação entre indivíduo e entorno cultural. Leontiev (2001) explicita, nesse sentido, que no percurso de desenvolvimento preponderam diferentes tipos de atividade como modos prevalentes de relação com o mundo circundante à vista do atendimento dos estados carenciais, o que significa dizer que a própria atividade, como mediação, forma-se e se desenvolve. Essa ideia sintetiza-se no conceito de atividade dominante, que altera-se a cada período do desenvolvimento da criança à medida que sua consciência vai se tornando capaz de captar novos e mais complexos aspectos e dimensões da realidade, em razão das novas capacidades de percepção e ação no mundo que se forjam no seio da própria atividade ${ }^{5}$.

${ }^{5}$ Atividades dominantes são aquelas que operam as transformações mais decisivas no desenvolvimento à medida que transformam e especializam as funções psíquicas e, consequentemente, a relação sujeito-objeto. Das pesquisas de Leontiev e Elkonin resulta a identificação e proposição das seguintes atividades-guia, em correspondência ao 
Ao debruçar-se justamente sobre o problema da periodização do desenvolvimento da atividade e da consciência, Elkonin (1987) chama atenção para o caráter objetal-instrumental de conteúdo da atividade humana, indicando a necessidade de se investigar com quais aspectos da realidade concreta a criança interage no curso de sua atividade. Na atividade objetalinstrumental da primeira infância, por exemplo, o foco da atividade consciente em formação são os modos sociais de ação com os instrumentos da cultura; já na brincadeira protagonizada, os modelos de relação humana consubstanciados em papéis sociais é que ocupam centralidade na atividade infantil. Toda atividade configura-se, assim, como processo que coloca a pessoa em relação com conteúdos específicos da vida social, no que se incluem costumes, tradições, conflitos, significados, valores, conhecimentos, habilidades etc. Com o exposto, queremos colocar em relevo o seguinte postulado: não há atividade humana isenta de conteúdo, no que se inclui a atividade escolar da criança.

Com base no referencial histórico-crítico, em diálogo com o destaque histórico-cultural ao caráter objetal da atividade humana, entende-se que a dimensão do conteúdo refere-se aos objetos de ensino, ou seja, a "o que" se ensina e se aprende; no contexto da discussão sobre o currículo escolar, o debate em torno do conteúdo aponta para os elementos da cultura dos quais o estudante deve apropriar-se para que se efetive a intencionalidade do trabalho educativo, qual seja, a (re)constituição da humanidade historicamente produzida pelo conjunto dos seres humanos em cada indivíduo singular.

É a partir do conceito histórico-cultural de atividade, com destaque a seu caráter objetal, que realizamos um esforço de aproximação ao conceito de experiência no âmbito do arranjo curricular por campos de experiência. Nosso ponto de partida é justamente o entendimento de que o conteúdo é um aspecto indelével da experiência humana no mundo. Essa tese é corroborada em nossa análise da BNNC e do documento complementar quando nos debruçamos sobre apresentação dos campos de experiência: a despeito do esforço de afastamento, por parte dos proponentes, da referência a conteúdos escolares, o que se constata é que as experiências infantis preconizadas na política têm conteúdo! Esse é, em nossa avaliação, um importante nexo para a elaboração de currículos de orientação histórico-crítica que não deixem de atender as normativas da Base. No quadro abaixo, buscamos sistematizar, a título de primeira aproximação, aquilo que os próprios documentos oficiais indicam ao explicar

período do desenvolvimento: comunicação emocional direta bebê/adulto (primeiro ano de vida); atividade objetalinstrumental (primeira infância); jogos simbólicos (idade pré-escolar), atividade de estudo (idade escolar); atividade de comunicação íntima pessoal e preparação profissional/estudo (adolescência inicial e adolescência, respectivamente), possibilitando-nos inferir o trabalho como atividade-guia da idade adulta. 
os campos de experiência, e que entendemos tratarem-se dos conteúdos nucleares das experiências infantis vislumbradas para os diversos campos.

Quadro 1: Conteúdos nucleares das experiências infantis identificados mediante análise histórico-crítica da BNCC e documento complementar que versa sobre campos de experiência

\begin{tabular}{|c|c|c|}
\hline \multirow{2}{*}{$\begin{array}{l}\text { CAMPO DE } \\
\text { EXPERIÊNCIAS }\end{array}$} & \multicolumn{2}{|c|}{$\begin{array}{l}\text { CONTEÚDOS NUCLEARES DAS EXPERIÊNCIAS INFANTIS IDENTIFICADOS NA BNCC (E } \\
\text { DOCUMENTO COMPLEMENTAR) }\end{array}$} \\
\hline & $\begin{array}{l}\text { Área/ tema/ objeto de } \\
\text { experiência }\end{array}$ & $\begin{array}{l}\text { Conteúdos, recursos e atividades especificados nos } \\
\text { documentos }\end{array}$ \\
\hline $\begin{array}{l}\text { O eu, o outro e o } \\
\text { nós }\end{array}$ & $\begin{array}{l}\text { Identidade, alteridade e } \\
\text { coletividade. } \\
\text { Ciências da sociedade. }\end{array}$ & $\begin{array}{l}\text { - hábitos de autocuidado, autoconhecimento, } \\
\text { autoestima e autonomia; } \\
\text { - construção de laços afetivos, senso de } \\
\text { reciprocidade e interdependência; } \\
\text { - regras de convívio social; } \\
\text { - pertencimento étnico-racial, territorial/ comunitário } \\
\text { e de gênero; } \\
\text { - diferentes grupos sociais e culturais: seus papéis } \\
\text { sociais, costumes, celebrações e narrativas). }\end{array}$ \\
\hline $\begin{array}{l}\text { Corpo, gestos e } \\
\text { movimentos }\end{array}$ & $\begin{array}{l}\text { Práticas selecionadas da } \\
\text { Cultura Corporal (dança, } \\
\text { jogos e brincadeiras e artes } \\
\text { circenses) } \\
\text { Arte Dramática }\end{array}$ & $\begin{array}{l}\text { - jogos e brincadeiras; } \\
\text { - possibilidades expressivas do corpo; controle e } \\
\text { adequação do uso do corpo em atividades diversas; } \\
\text { autonomia de movimentos e gestos (andar, correr, } \\
\text { saltar, saltitar, arrastar-se, equilibrar-se, pegar, } \\
\text { lançar, encaixar, empilhar, rasgar, amassar etc.); } \\
\text { orientação espacial; } \\
\text { - danças típicas da cultura de origem da criança; } \\
\text { aprendizado de outras modalidades de dança; } \\
\text { elementos expressivos na dança (postura corporal, } \\
\text { expressões faciais etc.); apreciação da dança e } \\
\text { criação de coreografias; } \\
\text { - teatro de bonecos, fantoches, de sombras ou } \\
\text { animação de objetos; elementos básicos de roteiros } \\
\text { dramatúrgicos. }\end{array}$ \\
\hline $\begin{array}{l}\text { Escuta, fala, } \\
\text { pensamento e } \\
\text { imaginação }\end{array}$ & $\begin{array}{l}\text { Língua materna/ Língua } \\
\text { portuguesa }\end{array}$ & $\begin{array}{l}\text { - modalidade oral (ou de sinais): formas sociais de } \\
\text { comunicação (conversas, cantigas, brincadeiras de } \\
\text { roda, parlendas, jogos cantados etc.); leitura de } \\
\text { histórias; sonoridade da língua; } \\
\text { - modalidade escrita: comportamento leitor; } \\
\text { instrumentos e suportes de escrita; gêneros } \\
\text { textuais; escrita do nome. }\end{array}$ \\
\hline $\begin{array}{l}\text { Traços, sons, } \\
\text { cores e imagens }\end{array}$ & $\begin{array}{l}\text { Artes Visuais } \\
\text { Arte Dramática } \\
\text { Música } \\
\text { Literatura }\end{array}$ & $\begin{array}{l}\text { - repertório musical (obras clássicas, populares, } \\
\text { étnicas, cantadas ou instrumentais, folclóricas } \\
\text { etc.), objetos sonoros, instrumentos musicais; } \\
\text { características do som: duração, altura, } \\
\text { intensidade, timbre; escuta ativa da música e } \\
\text { criação musical; } \\
\text { - brincadeiras cantadas, parlendas, rimas e jogos } \\
\text { musicais; }\end{array}$ \\
\hline
\end{tabular}




\begin{tabular}{|c|c|c|}
\hline & & $\begin{array}{l}\text { - atividades produtivas: desenho; pintura; colagem; } \\
\text { fotografia; leitura de imagem; modelagem; } \\
\text { escultura; } \\
\text { - fundamentos das linguagens visuais: linhas, } \\
\text { formas, cores, volumes, planos (horizontal e } \\
\text { vertical), dimensões (bidimensional e } \\
\text { tridimensional); } \\
\text { - exploração de materiais como meio e suporte; } \\
\text { procedimentos de utilização e organização de } \\
\text { materiais; representação, expressão e apreciação. }\end{array}$ \\
\hline $\begin{array}{l}\text { Espaços, tempos, } \\
\text { quantidades, } \\
\text { relações e } \\
\text { transformações }\end{array}$ & $\begin{array}{l}\text { Conhecimentos sobre o } \\
\text { mundo físico e social } \\
\text { (ciências da natureza e } \\
\text { ciências da sociedade) } \\
\text { Conhecimentos matemáticos }\end{array}$ & $\begin{array}{l}\text { - espaço geométrico e geográfico: orientação e } \\
\text { percepção espacial, noções espaciais relativas a } \\
\text { situações estáticas ou dinâmicas, noção de } \\
\text { proporcionalidade, formas geométricas planas e } \\
\text { não planas, representação do espaço, paisagem } \\
\text { local e ocupação/uso do espaço nas cidades e no } \\
\text { campo. } \\
\text { - tempo físico e cronológico: categorias temporais: } \\
\text { ritmos, duração, orientação e medição; relação } \\
\text { entre tempo e espaço; noções de simultaneidade, } \\
\text { sequência, mudança e permanência; noções de } \\
\text { duração e intensidade. } \\
\text { - quantificação: contagem, classificação, seriação, } \\
\text { ordenação; medidas, comparação de massa, } \\
\text { comprimento e quantidades, avaliação de } \\
\text { distâncias; reconhecimento de números cardinais e } \\
\text { ordinais, série numérica oral e sistema de } \\
\text { numeração escrita; representação de quantidade. } \\
\text { - relações e transformações: regularidades e } \\
\text { irregularidades nos fenômenos físicos/naturais e } \\
\text { socioculturais; noções de causalidade e } \\
\text { transformação, identificação, reconhecimento e } \\
\text { compreensão de mudanças nos objetos e } \\
\text { fenômenos; transformação dos ingredientes nas } \\
\text { práticas culinárias. }\end{array}$ \\
\hline
\end{tabular}

Fonte: Elaborado pelas autoras.

A análise sistematizada nesse quadro tem como propósito evidenciar que a descrição dos campos de experiência no documento oficial da BNCC e particularmente no documento complementar "Campos de experiência: efetivando direitos e aprendizagens na educação infantil", ainda que procure afastar-se da referência às áreas de conhecimento, aponta conteúdos culturais e histórico-sociais que podem e devem compor e enriquecer as experiências infantis, ideia que sintetizamos acima ao postular que as experiências infantis preconizadas na política têm conteúdo. Sem pretensão de formular uma análise exaustiva dos documentos em tela, o que queremos aqui é destacar que Arte, Ciência, Cultura Corporal, Língua materna e Matemática fazem-se presentes na política quando se indicam caminhos para efetivação do trabalho pedagógico que proporcione "experiências ricas e diversificadas" (FUNDAÇÃO SANTILLANA, 2018, p. 30) que colaborem para "ampliar o desenvolvimento pleno das 
crianças" (p. 28). A partir daquilo que identificamos como conteúdos nucleares das experiências infantis, decodificados a partir de conteúdos, recursos e atividades preconizados na política, entendemos que é possível encontrar caminhos para a elaboração de propostas curriculares de corte histórico-crítico que não abram mão do conhecimento como eixo articulador fundamental do trabalho pedagógico, e assim fazendo não apenas garantem mas vão além dos seis direitos de aprendizagem fixados pela BNCC, a eles agregando o direito a conhecer o mundo.

Defendemos que a seleção de quais conteúdos da cultura deverão ser garantidos às crianças como esteio de suas experiências é tarefa de primeira ordem na educação infantil, o que significa dizer que, quando se trata de elaborar e implementar propostas curriculares, não basta levantar a bandeira do lúdico se não se explicitar quais os conteúdos com os quais a criança poderá se relacionar de forma lúdica. Desde a referência histórico-cultural e históricocrítica, as experiências escolares infantis podem ser concebidas, a partir de Leontiev (1978), como processos de apropriação e objetivação da cultura humana, compreendendo-se o processo de apropriação em seu caráter ativo, educativo e desenvolvente (PASQUALINI; EIDT, 2019), instituinte da imagem consciente da realidade objetiva que orienta a ação no mundo (MARTINS, 2013). Os conteúdos identificados mediante análise documental da BNCC e documento complementar e sistematizados no quadro 1 serão, assim, objeto de apropriação pelo aluno da educação infantil mediante o que Vygotski (1996) denominou obutchénie, a atividade compartilhada e guiada por um par mais desenvolvido, processo pelo qual se reconstituirão na criança as capacidades motoras e psíquicas elaboradas e conquistadas pelos seres humanos no curso da História - em suma, mediante o ensino! $\mathrm{Na}$ ausência do ato educativo que seleciona conteúdos e enriquece a vivência escolar infantil, o que se coloca como tendência é a reprodução do cotidiano alienado, reproduzindo opressões e preconceitos que os próprios objetivos proclamados dos documentos em análise pretendem combater. É preciso, em última análise, reconhecer a diretividade invisível das experiências cotidianas, que não é suprimível - e, ao contrário, fortalece-se - com a recusa à diretividade visível da experiência educativa do aluno.

Assumindo tal concepção afirmativa do ato de ensinar (DUARTE, 1998) como promotor, por excelência, do desenvolvimento humano, pontuamos que os campos de experiência propostos pela BNCC necessitam ser compreendidos a partir da situação social de desenvolvimento da criança atendida pela educação infantil, recuperando a propositura histórico-cultural que evidencia que a atividade humana articula, sempre, o polo sujeito e o polo objeto - ou seja, a pessoa e as circunstâncias dadas às suas ações. Destacamos, assim, o conceito de situação social de desenvolvimento (VYGOTSKI, 1996) como referência à relação única e 
irrepetível entre a criança e o mundo que marca cada período do desenvolvimento infantil, articulado, intrinsecamente, ao conceito de atividade dominante. Uma proposição curricular para a educação infantil deverá orientar-se por essa análise, trazendo o princípio históricocrítico da tríade conteúdo-forma-destinatário (MARTINS, 2013) como fundamento e caminho para a articulação com os campos de experiência, que se apresentam como requisito legal. Isso significa que é preciso considerar que a experiência da criança na escola se requalifica a cada novo período do desenvolvimento, permitindo que ela se aproprie de novas esferas do existir humano objetivadas nas produções da cultura, instrumentalizando-se, assim, para também objetivar-se no processo histórico. A riqueza cultural e humana dos processos de apropriação e objetivação que se produzirão no espaço escolar depende diretamente do trabalho pedagógico, que seleciona os conteúdos da cultura historicamente acumulada e elege as formas mais adequadas para organizar a atividade infantil de modo que nela se reconstitua a atividade histórico-cultural do gênero humano.

Ao destacarmos a tríade conteúdo-forma-destinatário, queremos enfatizar que a educação infantil possui características peculiares, advindas da faixa etária atendida, de sorte que o trato com os conteúdos e formas de ensino também conquistam especificidades, dentre as quais a necessidade de distinção entre conteúdos de natureza operacional e conteúdos de natureza teórica, tal como proposto por Martins (2009). Trata-se, grosso modo, da distinção entre conteúdos que são diretamente ensinados e aprendidos pelas crianças em seus conteúdos conceituais, e conhecimentos que, indiretamente, fundamentam a ação do professor em suas intervenções educativas desenvolventes.

A formulação da autora visa lançar luz a uma particularidade da educação infantil que, não raro, é erroneamente interpretada como ausência ou impertinência de conteúdos no trabalho pedagógico com os bebês e crianças pequenas. Notadamente nos dois primeiros anos de vida, a práxis pedagógica tem como alvo a formação operacional da criança, sendo ainda restritas as possibilidades de transmissão-apropriação de conteúdos de natureza verbal e conceitual. São necessárias diversificadas intervenções educativas que atuam no sentido de promover a formação das premissas da fala antes de podermos ensinar diretamente o significado de uma palavra à criança, por exemplo. No primeiro caso, trabalha-se no âmbito da formação de operações e ações, isto é, na formação operacional, ao passo que no segundo começa-se a adentrar a formação propriamente teórica, progressivamente lidando com conteúdos conceituais. Segundo Martins (2009), conteúdos de formação operacional abarcam os conhecimentos interdisciplinares sob domínio do professor e orientadores de suas ações educativas, tendo em vista o desenvolvimento (na criança) de novos domínios, expressos em 
habilidades e capacidades operativas, a exemplo dos domínios locomotores, da fala, autocuidados, etc. Já os conhecimentos de natureza teórica compreendem aqueles que são transmitidos direta e planejadamente em seus conteúdos conceituais. Visam a superação gradual de conhecimentos sincréticos e espontâneos, por parte da criança, em direção à apropriação teórico-prática do patrimônio intelectual da humanidade. Um projeto pedagógico de orientação histórico-crítica baliza-se pelo entendimento da progressiva inversão de prevalência entre conteúdos de formação operacional e conteúdos de formação teórica no percurso da educação infantil.

Considerando a prevalência dos conteúdos de formação operacional no decorrer da primeira infância (aqui considerada como primeira época do desenvolvimento), o trabalho pedagógico necessita fundamentar-se cientificamente em diversas ciências/áreas do conhecimento, com destaque a: linguística, fonoaudiologia, psicologia, educação física, arte, literatura, matemática, dentre outras. Tal embasamento se faz necessário para que se possam atingir o que consideramos ser objetivos nucleares de ensino ao longo da primeira infância: a) superação dos sistemas comunicacionais imediatos em direção à conquista da linguagem oral, no primeiro ano de vida; b) aquisição de linguagem compreensiva e primórdios da fala (dos sons às palavras), no segundo ano de vida; c) domínio da linguagem oral/fala (das palavras às frases), a partir do terceiro ano de vida; d) progressiva e abrangente apropriação dos nomes dos objetos, suas propriedades, funções e modos sociais de uso; e) conquista dos domínios locomotores (sensomotricidade), com destaque progressivo à marcha e à coordenação óculomanual, visando ao autodomínio da conduta locomotora.

Na transição à idade pré-escolar, é fundamental que o trabalho pedagógico proporcione experiências de conteúdo desafiador ao psiquismo infantil em formação, com vistas à ampliação e aprofundamento: do domínio da linguagem, como meio de comunicação e autorregulação da conduta, promovendo a ampliação de vocabulário e o trânsito das frases às orações; da atividade objetal-instrumental, como condição de ampliação do repertório de ações com objetos e base para a atividade lúdica imaginativa; e dos domínios locomotores, com ênfase na apropriação de fundamentos basilares da Cultura Corporal e possibilidade de autorregulação das ações corporais, incluindo operações gráficas - tendo em vista a pré-história da escrita e a própria formação embrionária da atividade de estudo. Ganham relevância nesse período do desenvolvimento a orientação no tempo e no espaço, as noções introdutórias de números, numerais, quantidades e medidas; a compreensão elementar dos fenômenos da natureza e da sociedade, pautada nas Ciências; e a formação da dimensão estética da consciência, pautada por processos de apropriação da Arte. Evidenciamos, ainda, a relevância da formação da capacidade 
de planejar ações e executá-las em conformidade com o planejado, a qual encontra nas atividades produtivas mediação privilegiada de desenvolvimento (MUKHINA, 1996).

Entendemos importante acentuar que as indicações acima, com as quais buscamos sinalizar caminhos para a formulação de objetivos de ensino relevantes para a promoção do desenvolvimento em suas máximas possibilidades nos períodos do desenvolvimento contemplados pela educação infantil, contemplam plenamente os objetivos de aprendizagem e desenvolvimento preconizados pela $\mathrm{BNCC}$, cujo caráter minimalista necessita ser assinalado. Um currículo de orientação histórico-crítica para a educação infantil deve necessariamente formular objetivos que superem - por incorporação - aqueles apontados pela Base Nacional, assumindo o compromisso com a formação omnilateral da criança.

\section{Considerações finais}

A jovem história da Educação Infantil brasileira se faz marcada por desafios incomensuráveis, com destaque: à escassez de recursos para o financiamento das instituições destinadas às crianças pequenas, notadamente no que tange às exigências de formação profissional e salarial de seus quadros; à indefinição de sua identidade pedagógica, que a mantém refém de ideários desescolarizantes ancorados no binômio artificial consagrado como "cuidar e educar"; a manutenção de concepções fetichizadas, naturalizantes e não historicizadoras acerca da infância, etc. O saldo dessa história não é outro, senão, a inexistência, em pleno século XXI, da consolidação das escolas de educação infantil como espaços educativos mediadores entre as esferas cotidiana e não cotidiana da vida das crianças.

O pedagogismo espontaneísta, a reiteração da cotidianidade e a prevalência de conhecimentos de senso comum persistem, ainda que embalados em invólucros bastante sedutores a exemplo do "respeito à infância". Com isso, na mais absoluta desqualificação do ensino dos conhecimentos historicamente sistematizados, a atenção educativa destinada às crianças pequenas permanece pautada por um trabalho educativo assistemático e orientado pelo pragmatismo da vida cotidiana. É sob tal conjuntura, marcada por um acirrado conflito de classes, que a Base Nacional Comum Curricular desponta vertendo o pêndulo da balança para o enfoque desescolarizante e minimalista no que se refere aos conhecimentos que veicula.

Com o presente artigo, esperamos contribuir com os notáveis esforços de pesquisadores e profissionais da Educação Infantil que, mesmo sabendo que "penteiam a contra pelo", não se curvam aos imperativos do capital e trabalham em prol de uma educação escolar pública desenvolvente, entendendo-a como direito de todos os indivíduos, independentemente da idade 
que tenham, precisam ser reconhecidos. A história da Educação Infantil brasileira também se faz marcada por trabalhos que, corajosamente, proclamam o ideal de emancipação humana e advogam a educação escolar a serviço da formação de sujeitos e não de sujeitados da história. A esse coletivo nos somamos. Entendendo que fazemos história, mas não a fazemos como queremos e sim a partir das condições com as quais nos defrontamos, almejamos ter sinalizado caminhos possíveis para seguirmos nessa nossa luta diante das condições que ora nos impõem as circunstâncias.

\section{REFERÊNCIAS}

BRASIL. Base Nacional Comum Curricular (BNCC). Brasília: MEC. 2017. Disponível em: http://basenacionalcomum.mec.gov.br/images/BNCC_20dez_site.pdf. Acesso em: 03 fev. 2020 .

COLL, C. Um marco de referência psicológico para a educação escolar: a concepção construtivista de aprendizagem e do ensino. In: COLL, C.; PALACIUS, J.; MARCHESI, A. Orgs.). Desenvolvimento psicológico e educação: psicologia da educação. Porto Alegre, Artes Médicas, v. 2, p. 389-406, 2, 1996.

DUARTE, N. Concepções afirmativas e negativas sobre o ato de ensinar. Cad. CEDES, Campinas, v. 19, n. 44, p. 85-106, 1998.

DUARTE, N. O currículo em tempos de obscurantismo beligerante. Rev. Espaço do Currículo (online), João Pessoa, v. 11, n. 2, p. 139-145, maio/ago. 2018.

ELKONIN, D. Sobre el problema de la periodización del desarrollo psíquico en la infância. In: DAVÍDOV, V.; SHUARE, M. (Orgs.). La psicologia evolutiva y pedagógica en la URSS (Antologia). Moscou: Editorial Progresso, p. 104-124, 1987.

LAMARE, F. F. Contradições na concepção de formação humana nas políticas de Educação Infantil no Brasil: o que revelam os documentos do período de 2003 a 2010. Orientadora: Marise Nogueira Ramos. 2016. 233 f. Tese (Doutorado em Políticas Públicas e Formação Humana) - Universidade do Estado do Rio de Janeiro, Rio de Janeiro, 2016.

LEONTIEV, A. N. Desenvolvimento do psiquismo. Lisboa: Livros Horizonte, 1978.

LEONTIEV, A. N. Uma contribuição à teoria do desenvolvimento da psique infantil. In: VIGOTSKII, L. S.; LURIA, A.; LEONTIEV, A. (Orgs.). Linguagem, desenvolvimento e aprendizagem. São Paulo: Ícone, p. 59-83, 2001.

MARTINS, L. M. A brincadeira de papéis sociais e a formação da personalidade. In: DUARTE, N.; ARCE, A. (Orgs.). Brincadeiras de papéis sociais na educação infantil. São Paulo: Xamã, p. 27-50, 2006. 
MARTINS, L. M. O ensino e o desenvolvimento da criança de zero a três anos. In: ARCE, A.; MARTINS, L. M. (Orgs.). Ensinando aos pequenos: de zero a três anos. Campinas: Alínea, p. 93-121, 2009

MARTINS, L. M. O desenvolvimento do psiquismo e a educação escolar. Campinas: Autores Associados, 2013.

MARTINS, L. M.; MAGALHÃES, G. M. A educação infantil e suas interfaces formais e informais. In: BIZELLI, J. L.; SOUZA, C. L. G. (Orgs.). Caminhos para a escola inclusiva. São Paulo: Cultura Acadêmica, 2014.

MARTINS, L. M.; MARSIGLIA, A. C. G. As perspectivas construtivista e históricocrítica sobre o desenvolvimento da escrita. Campinas: Autores Associados, 2015.

MARX, K. Para a crítica da economia política. In: MARX, K. Manuscritos EconômicoFilosóficos e outros textos escolhidos. v. 1. São Paulo: Nova Cultural, p. 3-25, 1987.

MUKHINA, V. Psicologia da idade pré-escolar. São Paulo: Martins Fontes, 1996.

PASQUALINI, J. C. Contribuições da psicologia histórico-cultural para a educação escolar da criança de 0 a 6 anos: desenvolvimento e ensino em Vigotski, Leontiev e Elkonin. Orientador: Newton Duarte. 2006. 206 f. Dissertação (Mestrado em Educação Escolar) - Universidade Estadual Paulista, Araraquara, 2006.

PASQUALINI, J. C. Proposta curricular para a educação infantil: a experiência de Bauru. Rev. Espaço do Currículo (online), João Pessoa, v. 11, n. 2, p. 154-167, maio/ago. 2018.

PASQUALINI, J. C.; EIDT, N. M. A educação como produção da humanidade na criança. In: MAGALHÃES, C.; EIDT, N. M. (Orgs.). Apropriações teóricas e suas implicações na educação infantil. Curitiba: CRV, 2019.

PIAGET, J. O nascimento da inteligência na criança. 4. ed. Rio de Janeiro: Zahar, 1982.

RUSSELL, B. História da filosofia ocidental. v. 4. São Paulo: Companhia Editora Nacional, 1969.

SAVIANI, D. Pedagogia histórico-crítica: primeiras aproximações. 8. ed. Campinas: Autores Associados, 2003.

VYGOTSKI, L. S. Obras escogidas. Tomo IV. Madrid: Visor, 1996. 


\section{Como referenciar este artigo}

PASQUALINI, Juliana Campregher; MARTINS, Lígia Márcia. Currículo por campos de experiência na educação infantil: ainda é possível preservar o ensino desenvolvente? Revista on line de Política e Gestão Educacional, Araraquara, v. 24, n. 2, p. 425-447, maio/ago., 2020. e-ISSN: 1519-9029. DOI: https://doi.org/10.22633/rpge.v24i2.13312

Submetido em: 10/12/2019

Revisões requeridas: $10 / 01 / 2020$

Aprovado em: 20/03/2020

Publicado em: 09/04/2020 